\title{
A Superação da hermenêutica subjetiva na teoria do conhecimento de Espinosa
}

KISSEL GOLDBLUM *

* PPGLM / IFCS

Mestrando no Programa de Pós-Graduação em Metafísica e Lógica

Instituto de Filosofia e Ciências Sociais, Universidade Federal do Rio de Janeiro.
RESUMO Na primeira parte da Ética, na qual Espinosa trata sobre Deus, o autor expõe a estrutura ontológica do mundo, baseada em uma substância única composta por infinitos atributos, cada um dos quais modificados por infinitos modos: "Pois além da substância e dos modos nada existe, e os modos nada mais são do que afecções dos atributos de Deus.” (SPINOZA, 2007, p. 51). Se além de Deus não pode existir outra substância, devemos compreender o homem como um modo de um atributo de Deus e não como uma substância separada da Natureza. Parte essencial da Ética, os gêneros de conhecimento, são as maneiras pelas quais é possível conhecer a substância e seus atributos. Estes mesmos gêneros do conhecimento têm sido, tradicionalmente, analisados da perspectiva de 'faculdades humanas' e consequentemente são compreendidos como resultado de interpretações, de uma hermenêutica subjetiva. Pretendo expor uma linha de análise que revela o processo de conhecer de maneira distinta, a saber: tomando-o como o próprio meio pelo qual Deus conhece a si mesmo, isto é, compreendendo o estudo da epistemologia espinosana como inerente à sua teoria ontológica. "Seus três gêneros do conhecimento não se referem a três gêneros de alguma faculdade humana; ao contrário, eles são as três maneiras pelas quais Deus conhece a sua própria natureza." (VINCIGUERRA, 2012, p.136). PALAVRAS-ChaVe Epistemologia; Ontologia; Ética; Conhecimento 


\section{A TEORIA DO CONHECIMENTO ANDA DE MÃOS DADAS COM A ONTOLOGIA}

Na primeira parte da Ética, o autor expõe a estrutura ontológica da natureza, baseada em uma substância única composta por infinitos atributos, cada um dos quais modificados por infinitos modos: "Pois além da substância e dos modos nada existe, e os modos nada mais são do que afecções dos atributos de Deus.” (SPINOZA, 2007, p. 51). Se além de Deus não pode existir outra substância, devemos compreender o homem como um modo de um atributo de Deus e não como uma substância separada da Natureza. "E é impossível que o homem não seja uma parte da natureza e que não siga a ordem comum desta." (SPINOZA, 2007, p. 353)

Parte essencial da Ética, os gêneros de conhecimento ${ }^{1}$, são as maneiras pelas quais é possível conhecer a substância e seus atributos. Estes mesmos gêneros do conhecimento têm sido, tradicionalmente, analisados da perspectiva de faculdades humanas e consequentemente, a substância e seus atributos compreendidos por meio de interpretações subjetivas. Pretendo expor uma linha de análise que revela o processo de conhecer de maneira distinta, a saber: tomando-o como o próprio meio pelo qual Deus conhece a si mesmo, isto é, compreendendo o estudo da epistemologia espinosana como inerente à sua teoria ontológica. O método espinosano rompe com a tradição que identifica o conhecimento como resultado do desenvolvimento de certas faculdades humanas.

Seus três gêneros do conhecimento não se referem a três gêneros de alguma faculdade humana; ao contrário, eles são as três maneiras pelas quais Deus conhece a sua própria natureza, modificada, como é, por modos infinitos e finitos, alguns dos quais humanos. (VINCIGUERRA, 2012, p.136) ${ }^{2}$

1 Cf. SPINOZA B. Ética, Parte II, Proposição 40 (2007, pp. 130-134). Os três gêneros do conhecimento, a saber, a imaginação, a razão e intuição estruturam aquilo que podemos chamar de teoria do conhecimento de Spinoza.

2 "His three kinds of knowledge do not refer to three different human faculties; instead, they are the three ways in which God knows his own nature, modified as it is by infinite and finite modes, some of them human ones." 
Desde, evidentemente, Aristóteles, a razão constituiu um império sobre a natureza, descobrindo novos campos, buscando revelar todos os seus significados. Neste sentido, a qualificamos como uma ferramenta segura no processo de conhecimento da natureza e na condução do homem à uma vida superior. Isto decorreu de uma má compreensão da relação substância/atributo/modo, que só pode ser verdadeiramente alcançada por meio do terceiro gênero, por meio da ligação singular, de cada parte com Deus. O método verdadeiro não busca otimizar alguma faculdade humana, mas entender as próprias forças pelas quais é possível compreender, ao entender o que é conhecer.

\section{OS LIMITES DA RAZÃo}

Uma compreensão mais apurada do pensamento espinosano, e principalmente da Ética, nos mostra que a razão, mesmo nos dando a ideia adequada ${ }^{3}$ da coisa, ainda não nos dá uma ferramenta capaz de entender a natureza, porque, inexoravelmente, ainda nos mantém imersos em uma hermenêutica subjetiva, baseada no primeiro gênero de conhecimento. A razão permanece assim em uma gramática dos signos.

Quero mostrar que o maior objetivo de Espinosa é direcionar nosso intelecto para compreender a Natureza através da intuição, como ele afirma na Parte V da Ética, “O esforço supremo da mente e sua virtude suprema consiste em compreender as coisas por meio do terceiro gênero de conhecimento." (SPINOZA, 2007, p. 393). Neste caminho necessitamos desqualificar o papel que fora dado, exclusivamente, à razão como ferramenta epistemológica capaz de compreender a natureza. Tampouco, devemos excluí-la do processo de conhecimento, mas sim, identificar suas verdadeiras funções na dinâmica dos gêneros do conhecimento.

Enquanto não nos esforçarmos para alcançar a compreensão das coisas por meio do ponto de vista da eternidade, segundo Espinosa, não seremos capazes de superarmos as interpretações da imaginação para produzirmos nossas próprias vidas: "Vemos, pois, que todas as noções que o vulgo costuma utilizar para explicar a natureza não passam de modos de imaginar e não indicam a natureza das coisas, mas apenas a constituição de sua própria imaginação.” (SPINOZA, 2007, p.73)

3 Cf. SPINOZA, Ética II, p.40, Escólio 1. 


\section{UMA INSERÇÃO NA TOTALIDADE DO CONHECIMENTO ANDA DE MÃOS DADAS COM A ONTOLOGIA}

Se o que existe é a substância, seus atributos e seus modos, o homem deve ser compreendido como um modo do atributo de Deus e não como uma substância separada da Natureza. Neste sentido, a epistemologia de Espinosa está baseada na compreensão da substância da qual o próprio homem é uma modificação, ou seja, não é uma busca pela verdade após o acúmulo de certas ideias, ou de certo padrão ético, moral, religioso ou qualquer outro tipo de conjunto determinado de ideias a respeito de um determinado método prévio que tematiza nosso acesso a tais verdades ${ }^{4}$.

O homem também é um corpo, e como tal, um modo do atributo extenso da substância. Podemos conceber os homens como pontos de vista, de tal maneira que, para o absoluto, os pontos de vistas não são exteriores. A substância compreende em si a infinidade de seus próprios pontos de vista por meio dos três gêneros do conhecimento.

Espinosa nos apresenta um método que, através de uma investigação ontológica e epistemológica, pode conhecer os modos dos atributos ${ }^{5}$ da Natureza a partir de sua inserção na totalidade. Neste sentido, podemos compreender quando Vinciguerra escreve que "a teoria do conhecimento anda de mãos dadas com a ontologia" (VINCIGUERRA, 2012, p.131) ${ }^{6}$. É fundamental o estudo da ontologia para compreender o que é entender, ou seja, a investigação da "genealogia da essência da substância" (DELEUZE, 1968, p.10)7. O conhecimento ontológico é o próprio conhecimento.

Cf. SPINOZA, B. Tratado de Correção do Intelecto, \$30-50, (1974, pp. 56-61). O método que Spinoza adota é um método radicalmente reflexivo, e como tal, não se baseia em uma busca prévia por padrões da verdade, tal como o Discurso do método de Descartes. Neste sentido, Spinoza não está propondo um movimento em direção à beatitude, ou à busca pela verdade, ou se se quer, uma busca qualquer. Por exemplo, a busca de um sistema político econômico, uma ideologia, um sistema religioso a que precisaríamos nos adequar, seguir, como religiões, ideologias etc. Spinoza revela que a única maneira de compreender alguma coisa é compreendendo como eu posso compreender uma ideia verdadeira dada.

5 Cf. SPINOZA B. Ética, Parte I, Definições 4, §4.

6 "theory of Knowledge goes hand in hand with ontology."

7 “...génealogie de l'essence de la substance.” 


\section{INTERPRETAÇÃO E OS SIGNOS DA IMAGINAÇÃO - O PRIMEIRO GÊNERO DO CONHECIMENTO}

Imaginar é conectar imagens ou significar coisas conectando imagens. E como a compreensão da série das imagens é particular ao intérprete, os significados da imaginação também serão. Por exemplo, o som articulado pomum faz sentido para alguém que fala latim, mas para alguém que fale português não fará sentido. A imaginação conecta imagens de forma particular: "Elas variam, em cada um, em razão da coisa pela qual o corpo foi mais vezes afetado, e a qual a mente imagina mais facilmente.” (SPINOZA, 2007, p.133)

Pomum não significa nada se não for interpretado por alguém que conheça este código linguístico, da mesma maneira que uma marca em uma pedra não significa nada sem ninguém que possa interpretá-la, produzindo algum sentido. Para Vinciguerra, neste jogo de significação, não é somente homens que participam, mas outros indivíduos, como pássaros, plantas, pedras, todos, que, capazes de serem afetados por essas marcas, produzem alguma significação. “Então, imaginação é uma interpretação cósmica dos sinais, e o panpsiquismo espinosano tende a um gênero muito especial de pansemiótica."8 (VINCIGUERRA, 2012, p 5)

Além de estar familiarizado com o código linguístico, podemos notar que, novamente, se você escutar o som "bomba" e for um confeiteiro, vai pensar que se trata de um doce, se for uma pessoa com fome no momento, significará alguma coisa para comer, se for um soldado em campo de batalha, significará uma bomba bélica etc. Podemos concluir que, no fim das contas, a cadeia de significados é direcionada pelo apetite. “Logo, a vontade e o intelecto é uma só e mesma coisa.” (SPINOZA, 2007, p.147)

Toda interpretação é necessariamente subjetiva, seja de uma formiga, que interpreta, de certa maneira, uma pegada de um animal na areia e assim modifica o seu caminho, ou um filósofo que interpreta um conceito metafísico. Todos os corpos são capazes de interpretar e esta interpretação precisa estar fundamentada na teoria das afetos, que fundamenta aquilo que podemos chamar de física espinosana. Espinosa nos revela que, como a “cadeia das imagens são sempre específicas de um intérprete particu-

8 "Thus, imagination is a cosmic interpretation of signs, and Spinozistic panpsychism tends to a very special kind of pansemioticism " 
lar, as leis das suas interconexões (concatenatio) precisam ser encontradas no hábito (consuetudo) do intérprete." (VINCIGUERRA, 2012, p 5)9

Antes de passar para o segundo gênero de conhecimento, vale ressaltar que o primeiro gênero do conhecimento - a imaginação - envolve necessariamente o intérprete e as marcas de sua vida. A ferramenta epistemológica que pretende criar signos, dar significado, não é a razão, mas a imaginação, “a causa das noções ditas comuns e que constituem os fundamentos de nossa capacidade de raciocínio.” (SPINOZA, 2007, p.131)

\section{O SEGUNDO GÊNERO DE CONHECIMENTO - A RAZÃo}

por exemplo, por ter ouvido ou lido certas palavras, nós recordamos das coisas e delas formamos ideias semelhantes àquelas por meio das quais imaginamos as coisas. Por termos, finalmente, noções comuns e ideias adequadas das propriedades das coisas. A este modo me referirei como razão ou conhecimento de segundo gênero. (SPINOZA, 2007, p. 135)

A razão para Espinosa é o meio pelo qual podemos ter a ideia adequada da coisa, ou seja, é a ferramenta epistemológica que, utilizando as imagens da imaginação, é capaz de formar ideias universais ${ }^{10}$, “Devemos observar que estas noções comuns não são formadas por todos da mesma maneira." (SPINOZA, 2007, p. 133)

As ideias adequadas formadas pela razão são aquelas que formamos após analisar as ideias comuns, percebidas de forma mutilada e confusa pela imaginação, passa a conhecer a causa, ou seja, a maneira pela qual determinado ente se produziu, seja extensionalmente através de encontros de corpos, ou no pensamento, através do relacionamento de ideias.

Gabriel Leitão, em seu artigo, “O problema da Linguagem em Espinosa”, expõe a diferença pela qual idiomas distintos apresentam o mesmo pensamento, entendendo a necessidade de conhecer as leis imanentes a cada idioma, a fim de permitir a interpretação correta dos textos. Esta estrutura imanente da linguagem está intimamente relacionada com o seu significado:

9 "Since chains of images are always specific to particular interpreters, the laws of their interconnection (concatenatio) must be found in the habit (consuetudo) of the interpreter."

10 Cf. SPINOZA B. Ética, Parte II, Proposição 40, Escólio 1. 
o problema da linguagem não apenas não é um problema secundário na filosofia de Spinoza como poderia sem dificuldades ser apresentado como um problema central, intimamente relacionado com a mitigação do papel enganador e passional da imaginação e de sua reorientação virtuosa, passo importante no caminho para a beatitude. (LEITÃO, 2015, p.12)

Utilizando apenas os dois primeiros gêneros do conhecimento, o homem só é capaz de compreender a Natureza através de signos, ele fica em uma gramática de signos da verdade; todavia, aqueles que buscam sinais da felicidade ou beatitude vivem imersos na imaginação. A felicidade ou beatitude é alcançada no momento em que se compreende a substância. Não é uma busca pela verdade, é uma compreensão da sua própria natureza: “A beatitude não é o prêmio da virtude, mas a própria virtude; e não a desfrutamos porque refreamos os apetites lúbricos, mas, em vez disso, podemos refrear os apetites lúbricos porque a desfrutamos.” (SPINOZA, 2007, p. 409)

Tudo segue a ordem divina, não porque Deus assim escolheu, i.e., por puro beneplácito, mas porque tudo segue da necessidade de sua natureza. O que quero ressaltar com esta breve exposição do segundo gênero do conhecimento, é que, a razão é um resultado de forças da natureza, um sintoma, no sentido que depende das ideias acumuladas pela imaginação. Entretanto, por mal compreender a Natureza e mesmo, o que seja compreender, designamos a razão como uma ferramenta capaz de compreender a Natureza e construímos uma sociedade nestes termos.

Não obstante, muitas vezes ignorado por comentadores, o que pretendo mostrar, é que para a teoria do conhecimento de Espinosa, a maneira correta para conhecer a Natureza é conhecendo a essência objetiva das coisas, cuja função cabe somente à intuição.

\section{O CONHECIMENTO VERDADEIRO NÃO DEPENDE DE UMA BUSCA POR IDEIAS VERDADEIRAS}

No Tratado da correção do intelecto, Espinosa nos revela que a maneira correta para entender alguma coisa só pode ser aquela que compreende a essência objetiva dessa mesma coisa: “Daí se vê que a certeza nada mais é que a própria essência objetiva, a saber, o modo como sentimos a essência formal é a própria certeza." (SPINOZA, 1973, p.58) E para compreender a essência objetiva não é necessário compreender a série das ideias que produz essas coisas na existência: "Efetivamente, também não é necessário que intelijamos a série delas, visto que as essências das coisas singulares 
e móveis não devem ser deduzidas da sua série ou ordem da existência." (SPINOZA, 1973, p.58) Para o autor, perceber alguma coisa por sua essência é simplesmente compreender sua verdade.

Por último, a coisa é percebida unicamente por sua essência quando, por saber algo, sei o que é saber alguma coisa, ou, por conhecer a essência da alma, sei que ela está unida ao corpo. Pelo mesmo conhecimento, sei que dois e três são cinco, e, dadas duas linhas paralelas a uma terceira, são também paralelas entre si. (SPINOZA, 1973, P.55)

O método é a compreensão da natureza do intelecto: “a parte principal do nosso método é inteligir otimamente as forças do intelecto e sua natureza." (SPINOZA, 1973, p. 75). Então, a maneira de compreender a essência formal só pode ser aquela que compreende o meio pelo qual eu posso conhecer.

Não existe a possibilidade do conjunto corpo-mente dar conta de todas as ideias, seria impossível para mente humana, compreender a totalidade da série que compõe as imagens da existência, "Não há um processo infinito no conhecimento, mas uma intuição imediata: eis o que podemos chamar de “cogito spinozano"' (SPINOZA, 1973, N.T, p. 55).

A verdade não necessita de signos, posto que o método verdadeiro não consiste em procurar o sinal da verdade, para só depois adquirir ideias; assim, os que procuram a verdade após o acúmulo de algumas ideias vivem estruturados na imaginação. Através da imaginação ${ }^{11}$, eu dou significado à imagem, eu dou significado ao resultado do processo de conhecimento dos dois primeiros gêneros (imaginação e razão), negligenciando o terceiro e mais importante. Não dou o salto necessário em direção à compreensão da natureza através da intuição. Este processo de significação da natureza rompe a estrutura do método do conhecimento espinosano, pois ele não alcança a intuição. Desta maneira, eu insistiria em dar conta da natureza dando-lhe significado, tentando dar conta da vida e conduzir o homem a uma vida superior somente através dos dois primeiros gêneros do conhecimento:

Como, pois, a verdade não necessita de nenhum sinal, mas basta ter as essências objetivas das coisas, ou, o que dá na mesma, as ideias, a fim de que se tire

11 Compreender a distinção entre imaginação e intelecto é parte fundamental do método spinozano "Evitamos, além disso, outra grande causa de confusão e que faz com que o intelecto não reflita sobre si mesmo, a saber, quando, não fazendo distinção entre a imaginação e a intelecção". 
toda a dúvida, daí se segue que não é o verdadeiro método procurar o sinal da verdade depois de adquirir as ideias, mas que o verdadeiro método é o caminho para que a própria verdade ou as essências objetivas das coisas ou as ideias (tudo isso quer dizer o mesmo) sejam procuradas na devida ordem. (SPINOZA, 1973, p.58)

Como inúmeros comentadores de Espinosa assim também enfatizaram, não existe signo na natureza ${ }^{12}$, ela não tem nenhum significado, a razão da existência é ela mesma. Vinciguerra, em “Mark, Image, Sign: A Semiotic Approach to Spinoza”, expõe de maneira clara a necessidade de abandonarmos, realmente, a ideia antropomórfica do conhecimento, se quisermos compreender a teoria do conhecimento de Espinosa: “Pode-se dizer e repetir que o ser humano não é uma substância, enquanto continua-se a pensar como se os seres humanos fossem seres substanciais, como a tradição ocidental desde Aristóteles nos ensinou.” (VINCIGUERRA, 2012, p.9) ${ }^{13}$

Se abandonarmos esta ideia, que, de acordo com Vinciguerra, mantivemos desde Aristóteles, dessa substância antropomórfica, que, utilizando a razão, pode compreender a Natureza, podemos, aí então, entender que o método não se baseia em encontrar ideias racionalmente verdadeiras ou racionalmente virtuosas. Concebendo corretamente aquilo que podemos chamar de teoria do conhecimento de Espinosa, vemos que ele não pretende entender a Natureza por meio da razão, tampouco descartá-la, mas compreender o seu verdadeiro papel em uma estrutura que só pode ser vislumbrada como tal em seu aspecto ontológico e cosmológico, e não do ponto de vista estritamente antropológico.

\section{A PERSPECTIVA DA ETERNIDADE E A NATUREZA EXPRESSIVA DA IDEIA}

Para o intelecto superar o ambiente imaginativo, devemos investigar a verdadeira função dos dois primeiros gêneros do conhecimento e direcionar o intelecto para a compreensão das coisas do ponto de vista da eternidade. O entendimento de alguma coisa por meio da perspectiva da eternidade não pode ter como objetivo analisar a

12 Principalmente o Deleuze dos Cursos de Spinoza, que utiliza a frase: "Existe expressões, nunca signos". (DELEUZE, 1978, p.32) do original “...la idea de signo no existe. Hay expresiones, nunca signos."

13 "One can say and repeat that the human being is not a substance, while continuing to think as if humans were substantial beings, as the Western tradition since Aristotle has taught us"'” 
soma de todas as coisas em particular, pois nesse caso estaria limitando a análise ao resultado da sua mente particular. O entendimento, por meio da compreensão da essência formal das coisas, é imediato, pois não é um processo de ação do pensamento, como expliquei nos parágrafos acima, não é um movimento de busca, é uma conscientização da verdade após o conhecimento de uma ideia verdadeira dada: "Por último, a coisa é percebida unicamente por sua essência quando, por saber algo, sei o que é saber alguma coisa.” (SPINOZA, 1973, p.55)

Tendo o homem um corpo e sendo parte, como tal, de um atributo da Natureza, ele está a todo momento realizando encontros com outros modos do atributo da extensão, em cada um dos quais assume características passivas e ativas ${ }^{14}$, i.e., se compondo ou se decompondo. O mesmo ocorre com as ideias no atributo do pensamento. Nesse sentido, podemos entender quando Epinosa nos explica uma parte fundamental do processo de conhecimento ${ }^{15}$ - para saber alguma coisa, preciso saber o que é o objeto desse saber, mas eu não preciso saber que sei. Ao contrário, para saber que eu sei que sei, eu preciso saber, preciso conhecer o objeto que eu tenho em mente, para poder dizer que eu conheço,"porque, para saber que sei, necessariamente devo antes saber. Daí se vê que a certeza nada mais é que a própria essência objetiva, a saber, o modo como sentimos a essência formal é a própria certeza.” (SPINOZA, 1973, p. 57) Podemos, assim, entender que antes de determinar um método para conhecer as coisas, eu preciso conhecer aquilo que se pode conhecer. E o conhecimento da verdade do ponto de vista da eternidade relaciona-se com a compreensão da natureza expressiva da ideia, e não de um signo prévio ou de um método que antecederia a posse das ideias verdadeiras. Isso fica particularmente na ideia de Deus: "Deus não dá um signo que remeteria a uma significação ou um significado (noção demente para Spinoza), ele se expressa, ou seja, ele revela as relações. E revelar não é nem simbólico e nem místico". (DELEUZE, 1978, p.32) ${ }^{16}$

14 Cf. SPINOZA, B. Ética, Parte III, Definições 2, (2007, p. 163).

15 Cf. SPINOZA, B. Tratado da correção do intelecto, (1974, p. 30).

16 "No da un signo que remitiría a una significación o a un significante (noción demente para Spinoza), él se expresa, es decir que revela relaciones. Y revelar no es ni místico, ni simbólico.” 
A expressão da ideia tem uma relação estrutural no processo de revelação; todavia, a tradição não cansou de nos mostrar como as ideias são formadas a partir do contato com os corpos externos. E, por conta disso, o vulgo tende a achar que as ideias não passam de meras ficções arbitrárias da mente.

Com efeito, aqueles que julgam que as ideias consistem nas imagens que em nós se formam pelo encontro dos corpos estão convencidos de que essas ideias das coisas das quais não podemos formar nenhuma imagem que se lhes assemelhe não são ideias, mas apenas ficções que fabricamos pelo livre arbítrio da vontade. (ESPINOSA, 2007, p. 147)

Deus se expressa, “existem expressões, nunca signos.” (DELEUZE, 1978, p.32) ${ }^{17}$. A expressão é própria unidade. Veritas se ipsam patefacit, “A verdade se mostra e se revela”. A tradição, ao caracterizar a mecânica epistemológica do processo de formação das ideias a partir do modelo imaginativo, ensinou que as ideias surgem como resultado dos encontros dos corpos. Esta opinião, baseada nas categorias do ver, negligencia o caráter expressivo da ideia e falseia o índice da verdade, que deveria estar na própria coisa ou em sua ideia. A ideia não surge como uma afecção do corpo na mente, tampouco pode ser definida por meio das palavras que usamos para expressá-la. A ideia é a expressão da coisa na mente, “portanto, compreenderá claramente que a ideia (por ser um modo do pensar) não consiste nem na imagem de alguma coisa, nem em palavras." (SPINOZA, 2007, p.147)

A expressão deve ser compreendida, de acordo com Deleuze, por meio de dois níveis da expressão. Em um primeiro nível, Deus se exprime por si mesmo antes de se exprimir por seus efeitos. Entendemos o primeiro nível por meio de uma "genealogia da essência da substância”18 (DELEUZE, 1968, p.10), que investiga a construção do conceito de substância e de seus atributos. O segundo nível é entendido por meio de cada modificação que se exprime por cada modo, por meio de uma investigação a respeito da produção de cada coisa.

17 "Hay expresiones, nunca signos".

18 "Presque une généalogie de l'essence de la substance." 
Os modos se deduzem da substância, como as propriedades deduzem-se de uma coisa definida; a análise de certo objeto é determinada pela investigação de sua causa; mas os atributos têm infinitas modificações. Como explicado acima, a teoria do conhecimento de Espinosa não conserva a epistemologia clássica, baseada no entendimento finito humano, que conclui as propriedades uma a uma, refletindo e a explicando uma coisa em relação com os outros objetos. A coisa que se exprime é o que é explicado. A expressão não é, portanto, objeto de demonstração, é a própria expressão que coloca a demonstração em termos absolutos, que faz da demonstração a manifestação imediata da substância infinita. É impossível compreender seus atributos sem tal intuição, ela é a manifestação daquilo mesmo que se expressa.

No necessria a presena de um intelecto humano, atento em encontrar a "ideia certa" ou "a resposta correta", porque, se no existe signo na natureza, tampouco existe significado. Espinosa estava preocupado em nos revelar a mecnica inerente a cada processo conceitual; nos mostrando o pensamento, como o prprio atributo da substncia, ele no conserva a ideia que a tradio manteve de estruturar o pensamento por meio de uma faculdade humana. A conscincia do mtodo espinosano nos possibilita um estado de tranquilidade imediata, jque liberta desta ideia de uma mente humana que precisa estar, tal como suposto tradicionalmente, "no controle da vida": "Assim, essa doutrina, alm de tornar nosso esprito inteiramente tranquilo, tambm nos ensina em que consiste nossa suprema felicidade, ou seja, nossa beatitude: unicamente no conhecimento de Deus." (SPINOZA, 2007, p. 147).

Acredito ter demonstrado a importância de analisarmos o método espinosano de maneira holística, afim de superarmos a epistemologia clássica, que pretende compreender o mundo e conduzir o homem a uma vida superior somente através da razão. Este processo envolve a conscientização dos conceitos que nos permitem compreender a verdade, num processo de análise reflexiva à causa da sua produção. E neste sentido, superar uma hermenêutica subjetiva da ideia do sujeito, em direção à compreensão da vida para além do ambiente dos significados da imaginação. Dessa forma, seria possível, segundo Espinosa, direcionar o intelecto para uma compreensão da eternidade do presente, que não está ligada às cadeias e séries de acontecimentos que 
constroem as imagens da existência. Este estado só pode ser alcançado com a compreensão exata do método, e o abandono da ideia do indivíduo antropomorfizado, em direção à compreensão da realidade por meio da perspectiva da eternidade através da ciência intuitiva.

\footnotetext{
"Pois, ao nível da racionalidade operatória que aqui se investigou, é evidente que a ciência produzida manipula as coisas sem habitá-las, sem se unir a elas e por elas ser habitada. Tal ciência não sente (gevoelen) e não frui (genieten) a coisa mesma, ela produz índices que funcionam como definições, mas que passam ao largo do que está concretamente dado (datorum numerorum), e trata seu objeto como "objeto em geral” (aliquid), construído sob medida para suportar as atribuições racionais de efeitos ou propriedades. Contra uma possível hegemonia dessa razão operatória entre as maneiras de perceber, Espinosa propõe uma emenda intuicionista". (NOVAES, 2004, p.60)
}

\section{BIBLIOGRAFIA}

SPINOZA, Baruch de. Tratado de Correção do Intelecto (traduzido por Marilena Chauí). $1^{\text {a }}$ edição. São Paulo: Editora Abril, 1973.

Baruch. Pensamentos Metafísicos (traduzido por Marilena Chauí) $1^{\mathrm{a}}$ edição. São Paulo: Editora Abril, 1973.

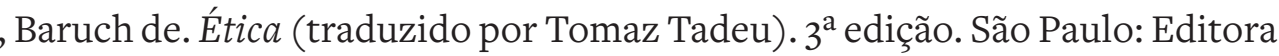
Autêntica, 2008.

DELEUZE, Gilles. Spinoza et le problème de l'expression. $2^{\mathrm{a}}$ edição. Paris: Editora Éditions de minu, 1969.

, Gilles. Curso sobre Spinoza (traduzido por Ernesto Hernández), 1978. Disponível em: http://reflexionesmarginales.com/3.o/wp-content/uploads/2013/o1/Gilles-Deleuze-Curso-Sobre-Spinoza.pdf Acesso em: 22/10/2016.

VINCIGUERRA, Lorenzo. Spinoza et le signe : La Genèse de l'imagination. $2^{\mathrm{a}}$ edição. Paris: Editora Librairie Philosophique J. Vrin, 2005. 
Lorenzo. “Mark, Image, Sign: A Semiotic Approach to Spinoza”. European Journal of Philosophy, 2012. Disponível em: http://sci-hub.cc/10.1111/j.1468-0378.2012.00523.x Acesso em: 22/10/2016.

LEITÃO, Gabriel. O problema da Linguagem em Spinoza, Linguagens e Diálogos, v.1, n.1, p. 24-41, Rio de Janeiro, 2010.

ULPIANO, Claudio. Palestra sobre Pensamento e Liberdade em Spinoza. USP, São Pau10,1988 .

NADLER, Steven. "Eternity and Immortality in Spinoza's Ethics”, Midwest Studies in Philosophy, XXVI, 2002.

PARCHMENT, Steven. The Mind's Eternity in Spinoza's Ethics, Journal of the History of Philosophy 38, p. 349-382, 2000.

NOVAES, Cristiano. Os perigos da razão segundo Espinosa: a inadequação do terceiro modo de perceber no tratado da emenda do intelecto, cad. hist. fil. ci., campinas, série 3, v. 14, n. 1, p. 59-118, 2004. 